\title{
Improving the voltage modulation depth and RF power generated on Nonlinear Transmission lines
}

\author{
L. P. Silva Neto \\ Institute of Science and Technology \\ São Paulo Federal University \\ São José dos Campos, Brazil \\ silvaneto007@yahoo.com.br
}

\author{
J. O. Rossi, J.J. Barroso, E. G. L. Rangel \\ Associated Plasma Laboratory \\ National Institute for Space Research \\ São José dos Campos, Brazil \\ rossi931@hotmail.com
}

\author{
E. Schamiloglu \\ Electrical and Computer Eng. Department \\ University of New Mexico \\ Albuquerque, USA \\ edls@unm.edu
}

\begin{abstract}
Nowadays Nonlinear Transmission Lines-NLTL have been studied for RF generation to be applied in different systems of communications such as satellite, military and biomedical applications. NLTL is built by using a network composed by inductors and capacitors, where at least one of these components need to have a nonlinear behavior. One limiting factor for applications is in the peak power range, and a way to increasing this is improving voltage modulation depth -VMD, which is main goal of this work. In this work, it is simulated and built three configurations of NLTLs using ceramic capacitors to improve VMD and consequently the RF power generated at the output. As shown by the results the cross-link configuration is the best method due to the highest VMD generated.
\end{abstract}

Keywords-soliton; voltage modulation depth; nonlinear transmission lines; varactor diode

\section{INTRODUCTION}

Recently Nonlinear Transmission Lines (NLTL) have been studied for several applications such as in satellite communications, military radars and biomedical area [1], [2]. This system is interesting due to its simple construction with the use of passive components composed by a network of inductors and capacitors as shown in the Fig. 1, where at least one of these components needs to be nonlinear. The line using nonlinear capacitor $\mathrm{C}(\mathrm{V})$ is denominated a nonlinear capacitive line (NLCL) and another one using inductor L(I) called nonlinear inductive line (NLIL). More details as soliton waves are generated at the output of NLTL can be found in earlier literature [3], [4].

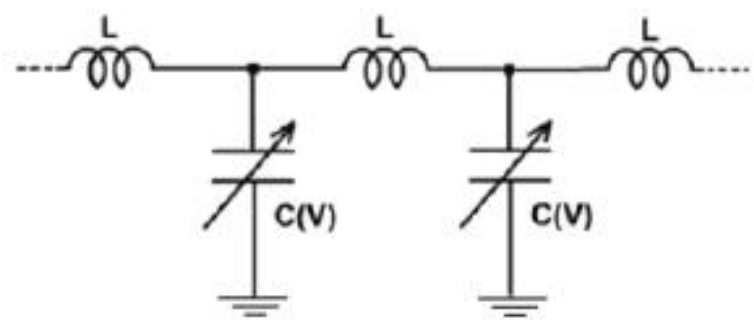

Fig. 1. The Nonlinear Transmission Lines using capacitors as nonlinear elements.

The NLTL using ceramic capacitors can reach hundreds of $\mathrm{kWs}$ for RF peak power [5]; however, to study their behavior in low power range varactor diodes are used as nonlinear elements. In this work three types of low power NLTLs were tested to obtain higher Voltage Modulation Depth (VMD). The first one uses parallel link capacitors with the varactor diodes, and the second employs parallel link capacitors with the inductors. Finally, the third one uses cross link capacitors intercalating adjacent NLTL sections [6].

\section{METHODOLOGY AND RESULTS}

In this section, it is shown the tests of low power NLTLs using varactor diodes as nonlinear elements and link capacitors to improve VMD. First, Fig. 3 shows the basic schematics of a NLCL with varactor diodes without link capacitors. The line consists of 30 sections built with the MV209 varactor diodes and $2.7 \mu \mathrm{H}$ linear inductors as described in [7] and considered here as a reference line. 


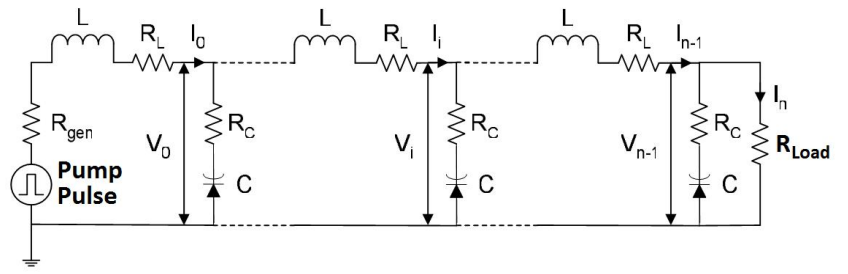

Fig. 3. A standard varactor diode line used to produce RF in the MHz range.

The output waveform obtained for reference line in Spice simulation is shown in Fig. 4, where the characteristics of the input pulse are: $15 \mathrm{~ns}$ rise time, $460 \mathrm{~ns}$ pulse width and peak voltage of $9.5 \mathrm{~V}$. The solitons generated at the output of reference line reach frequencies of the order of $40 \mathrm{MHz}$ with maximum VMD of about $9.0 \mathrm{~V}$.

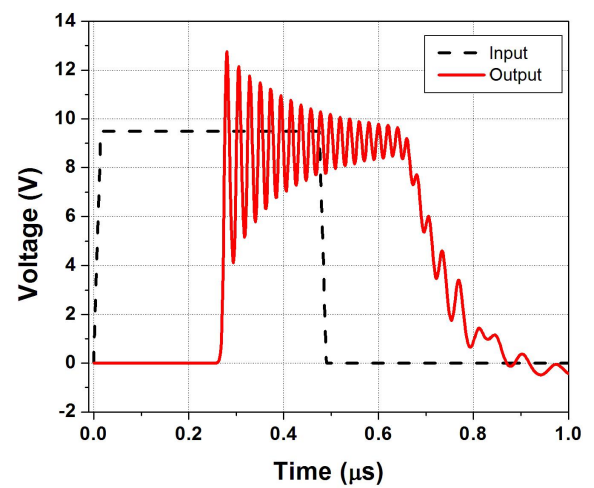

Fig. 4. The 30-section reference NLTL output waveform obtained using Spice simulation.

Using the same parameters adjusted for simulation input pulse, the experimental result shows a soliton generation with frequencies of the order $30 \mathrm{MHz}$ and $\mathrm{VMD}$ of approximately $8.8 \mathrm{~V}$ as seen in Fig. 5, giving a reasonable fitting to simulation given in Fig. 4.

The first configuration tested to improve the soliton generated at the output of NLTL with link capacitors in parallel with varactors is shown in Fig. 6. The line has the same basic configuration used for the reference line (see Fig. 3) and an additional link parallel capacitor placed at each line section.

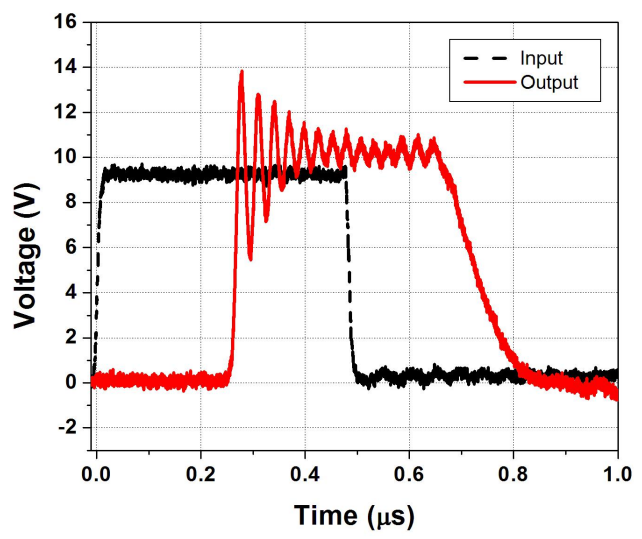

Fig. 5. The corresponding experimental waveform of the 30 -section reference NLTL.

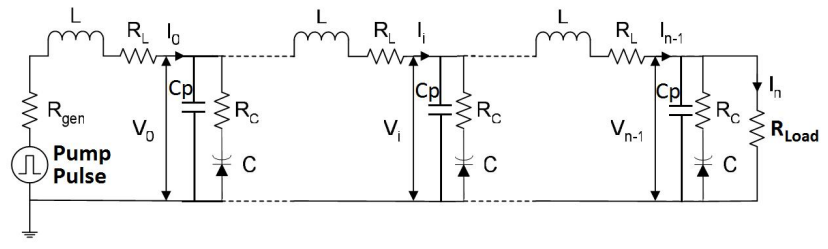

Fig. 6. A varactor diode line using parallel capacitor with diode.

Fig, 7 shows the Spice simulation of the output waveforms obtained for the first line configuration for three different values of link capacitors seen in Fig. 6. We can see in this graphic that by increasing $\mathrm{C}$ more VMD is obtained, but at the cost of decreasing frequency and increasing the line delay. To illustrate this a comparison between the results obtained in Spice simulation is shown in Tab. I.

The experimental results shown in Fig. 8 for the NLTL in Fig. 6 show a good agreement with the corresponding simulation as seen in Fig. 7. However, for the experimental case using $33 \mathrm{pF}$ ceramic capacitor less VMD is obtained than in the simulation because of the line losses. Tab. II gives all the parameters such as VMD, frequency and line delay obtained from Fig. 8, where the best case was for the 10-pF capacitor considering the compromise between higher VMD and frequency to be achieved.

TABLE I. PARAMETERS OBTAINED FROM NLTL SIMULATION USING PARALLEL LINK CAPACITOR WITH VARACTOR DIODE

\begin{tabular}{c|c|c|c}
\hline Parallel Cap & $\begin{array}{c}\text { VMD } \\
(\mathrm{V})\end{array}$ & $\begin{array}{c}\text { Frequency } \\
(\mathrm{MHz})\end{array}$ & $\begin{array}{c}\text { Delay } \\
(\mathrm{ns})\end{array}$ \\
\hline Reference & 8.65 & 40.0 & 260.0 \\
\hline $1 \mathrm{pF}$ & 9.70 & 38.0 & 265.0 \\
\hline $10 \mathrm{pF}$ & 10.98 & 29.4 & 305.0 \\
\hline $33 \mathrm{pF}$ & 12.50 & 19.2 & 382.0 \\
\hline
\end{tabular}

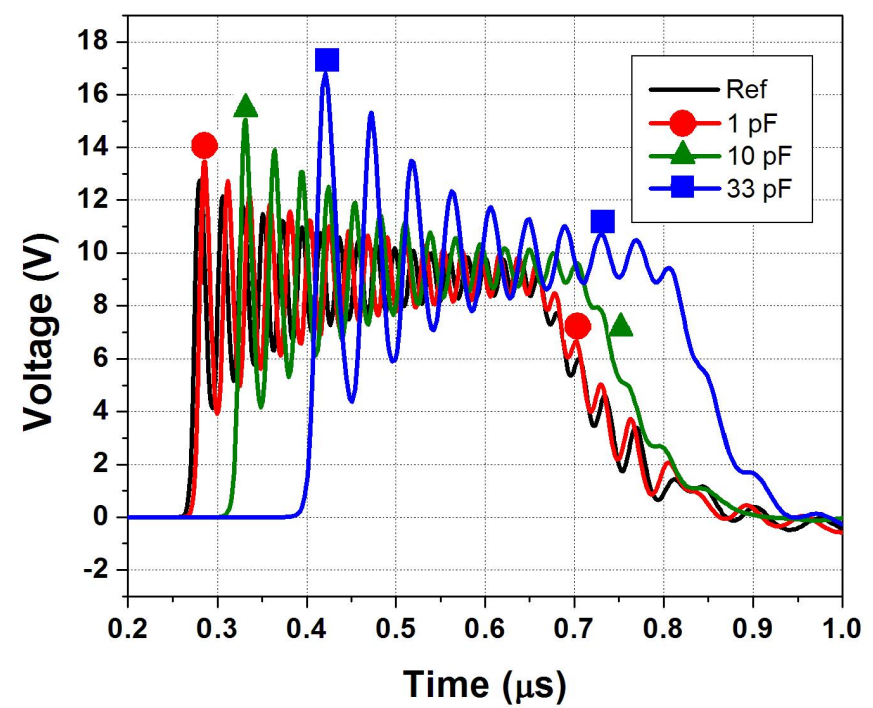

Fig. 7. The output waveforms obtained from Spice simulation for the line using parallel link capacitor with the varactor diode. 
TABLE II. PARAMETERS OBTAINED FROM NLTL TESTED USING PARALLEL LINK CAPACITOR WITH VARACTOR DIODE

\begin{tabular}{c|c|c|c}
\hline Parallel Cap & $\begin{array}{c}\text { VMD } \\
(\mathrm{V})\end{array}$ & $\begin{array}{c}\text { Frequency } \\
(\mathrm{MHz})\end{array}$ & $\begin{array}{c}\text { Delay } \\
(\mathrm{ns})\end{array}$ \\
\hline Reference & 8.14 & 30.0 & 250.0 \\
\hline $1 \mathrm{pF}$ & 9.20 & 29.4 & 255.0 \\
\hline $10 \mathrm{pF}$ & 9.54 & 23.2 & 286.0 \\
\hline $33 \mathrm{pF}$ & 8.80 & 17.2 & 369.0 \\
\hline
\end{tabular}

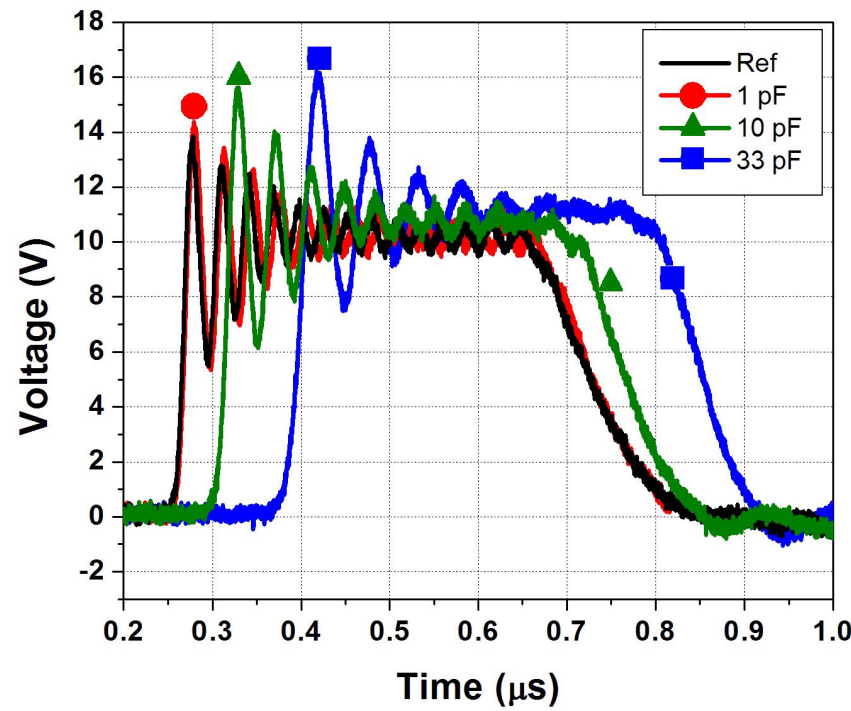

Fig. 8. The experimental output waveforms obtained for the line using parallel link capacitor with the varactor diode.

The second configuration tested to improve RF generation is the tuning line presented in the Fig. 9, where the ceramic capacitors are now in parallel with the line inductors.

By using tuning capacitor $\mathrm{C}_{\mathrm{p}}$ in the simulation of the NLTL it was obtained a VMD increase compared to the reference line, but at the cost of decreasing the frequency generated. The main characteristic of this configuration is that delay line is not affected as shown by simulation in Fig. 10. The corresponding parameters VMD, frequency and line delay also given in Tab. III.

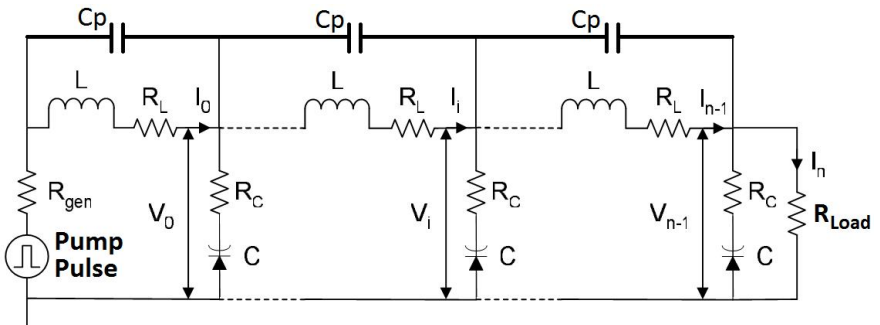

Fig. 9. A varactor diode line using parallel capacitor with inductor.
TABLE III. PARAMETERS OBTAINED FROM NLTL SIMULATION USING PARALLEL LINK CAPACITOR WITH LINE INDUCTOR

\begin{tabular}{c|c|c|c}
\hline Parallel Cap & $\begin{array}{c}\text { VMD } \\
(\mathrm{V})\end{array}$ & $\begin{array}{c}\text { Frequency } \\
(\mathrm{MHz})\end{array}$ & $\begin{array}{c}\text { Delay } \\
(\mathrm{ns})\end{array}$ \\
\hline Reference & 8.65 & 40.0 & 260.0 \\
\hline $1 \mathrm{pF}$ & 10.76 & 34.0 & 260.0 \\
\hline $10 \mathrm{pF}$ & 11.60 & 17.8 & 260.0 \\
\hline $33 \mathrm{pF}$ & 9.89 & 11.1 & 260.0 \\
\hline
\end{tabular}

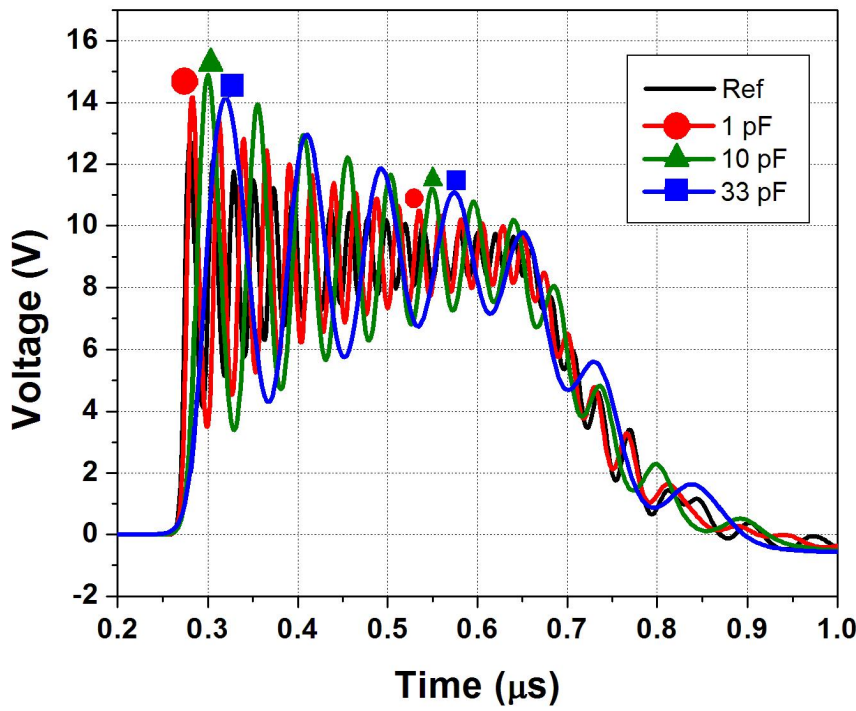

Fig. 10. The output waveforms simulated for the line using parallel link capacitor with line inductor.

For this line configuration, the experimental results and their corresponding main parameters are shown in Fig. 11 and Tab. IV, respectively. Again, as in former configuration the best case for higher VMD was with the $10-\mathrm{pF}$ ceramic capacitor, but with a drastic frequency decrease of $50 \%$ approximately as shown in Tab. IV.

TABLE IV. PARAMETERS OBTAINED FROM NLTL TESTED USING PARALLEL LINK CAPACITOR WITH LINE NDUCTOR

\begin{tabular}{c|c|c|c}
\hline Parallel Cap & $\begin{array}{c}\text { VMD } \\
(\mathrm{V})\end{array}$ & $\begin{array}{c}\text { Frequency } \\
(\mathrm{MHz})\end{array}$ & $\begin{array}{c}\text { Delay } \\
(\mathrm{ns})\end{array}$ \\
\hline Reference & 8.14 & 30.0 & 250.0 \\
\hline $1 \mathrm{pF}$ & 10.0 & 28.57 & 250.0 \\
\hline $10 \mathrm{pF}$ & 10.18 & 15.62 & 250.0 \\
\hline $33 \mathrm{pF}$ & 8.10 & 10.87 & 250.0 \\
\hline
\end{tabular}




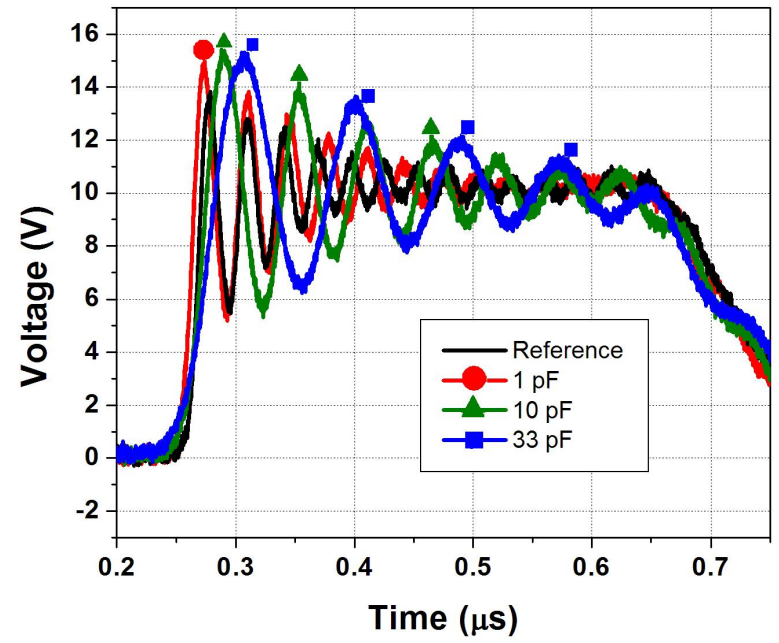

Fig. 11. The experimental output waveforms obtained for the line using parallel link capacitor with line inductor

The third line tested known as cross-link configuration was like that used by Kuek [7], where the capacitors are placed in parallel with two adjacent sections in such a way that their link terminals are crossed as shown in Fig. 12.

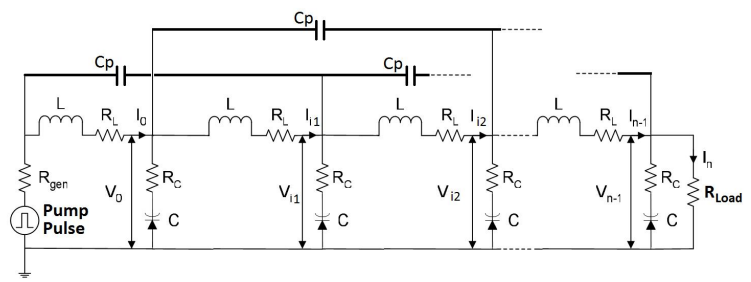

Fig. 12. NLTL schematics shown for cross-link configuration.

For cross-link configuration, simulation results in Fig. 13 seem very promising for generating oscillations with higher VMD. As shown in Tab. V, the best case detected was for the 1-pF capacitor, reaching the highest VMD of about $15 \mathrm{~V}$ at $27-$ $\mathrm{MHz}$ frequency. Again, as observed for the second (tuning) configuration, the use of cross-link capacitors does not affect the line delay as seen in Fig. 13. We can also see in Fig. 13 that increasing the value of capacitor distorts the soliton oscillations generated, being just for 1-pF capacitor the best-scenario case.

TABLE V. PARAMETERS OBTAINED FROM NLTL SIMULATION FOR CROSSLINK CONFIGURATION

\begin{tabular}{c|c|c|c}
\hline Parallel Cap & $\begin{array}{c}\text { VMD } \\
(\mathrm{V})\end{array}$ & $\begin{array}{c}\text { Frequency } \\
(\mathrm{MHz})\end{array}$ & $\begin{array}{c}\text { Delay } \\
(\mathrm{ns})\end{array}$ \\
\hline Reference & 8.65 & 40.0 & 260.0 \\
\hline $1 \mathrm{pF}$ & 15.32 & 27.0 & 260.0 \\
\hline $10 \mathrm{pF}$ & 12.73 & 11.2 & 260.0 \\
\hline $33 \mathrm{pF}$ & 9.00 & 6.5 & 260.0 \\
\hline
\end{tabular}

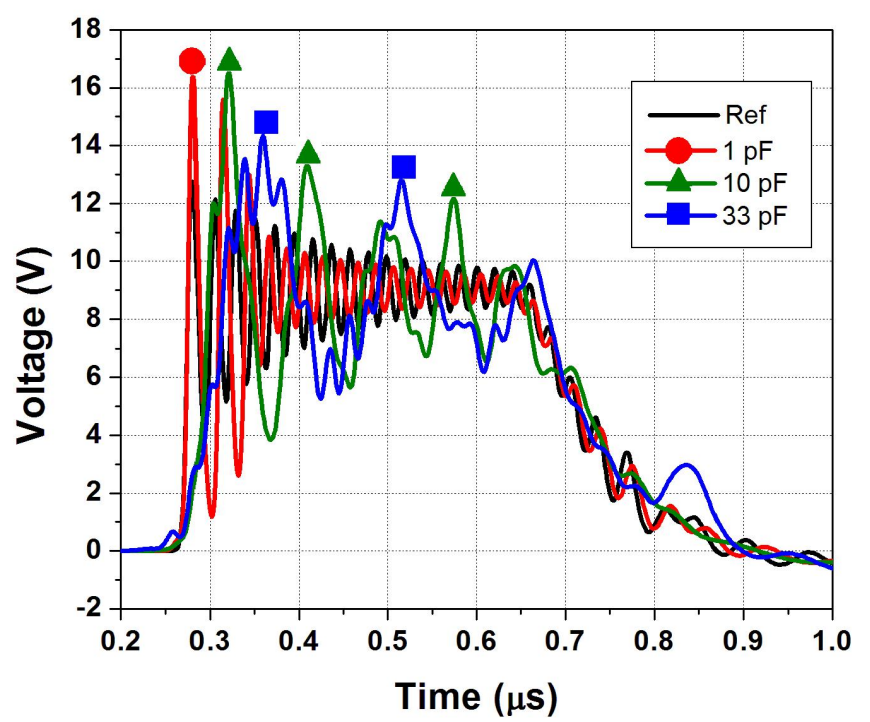

Fig. 13. The output waveforms obtained in the simulation of the NLTL cross link.

Confirming once more the applicability of the Spice program in NLTLs, experimental results for the cross-link case (see Fig. 14) and respective simulation in Fig. 13 are in a good agreement. As predicted by simulation, in this case line delay is not affected with the capacitance increase and the best VMD was confirmed for $\mathrm{C}=1 \mathrm{pF}$ with a value of about $11.6 \mathrm{~V}$, showing an increase of $42 \%$ compared to the reference line (see Tab. IV). However, as before in former cases as VMD is increased the oscillation is decreased. In this case, for $1-\mathrm{pF}$ capacitance frequency decreased from $30 \mathrm{MHz}$ for reference line to $24 \mathrm{MHz}$ approximately, having a drop of $20 \%$ in frequency. Table VI also shows the main parameters of the experimental results obtained for $10-\mathrm{pF}$ and 33-pF capacitors with lower performance. As shown by the waveforms in Fig. 14 for 10 and 33-pF capacitors, the output signals generated were degraded, being the worst case for the blue line with $\mathrm{C}=33 \mathrm{pF}$, which is according to the respective simulation seen in Fig. 13.

TABLE VI. PARAMETERS OBTAINED FROM NLTL TESTED FOR CROSS-LINK CONFIGURATION

\begin{tabular}{c|c|c|c}
\hline Parallel Cap & $\begin{array}{c}\text { VMD } \\
\text { (V) }\end{array}$ & $\begin{array}{c}\text { Frequency } \\
(\mathrm{MHz})\end{array}$ & $\begin{array}{c}\text { Delay } \\
(\mathrm{ns})\end{array}$ \\
\hline Reference & 8.14 & 30.0 & 250.0 \\
\hline $1 \mathrm{pF}$ & 11.62 & 24.3 & 250.0 \\
\hline $10 \mathrm{pF}$ & 8.73 & 9.6 & 250.0 \\
\hline $33 \mathrm{pF}$ & 7.55 & 6.1 & 250.0 \\
\hline
\end{tabular}




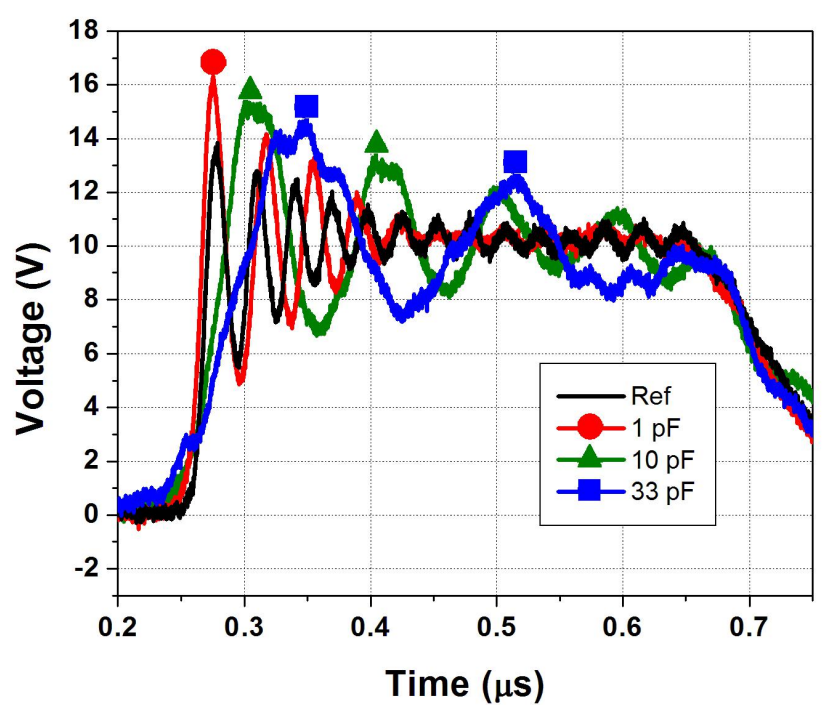

Fig. 14. Experimental NLTL with cross link configuration.

\section{CONCLUSIONS}

In this work, three configurations of low power NLTLs were built and simulated using varactor diodes as nonlinear elements and ceramic capacitors to tune the line. As shown by experimental results, there is a good agreement with the corresponding simulations. In the first configuration tested with link ceramic capacitors in parallel with varactors, the best-case scenario was found for $\mathrm{C}=10 \mathrm{pF}$ with increased VMD of the order of $1.40 \mathrm{~V}$, giving approximately $37 \%$ of increase in peak power. The tested second configuration used link ceramic capacitor in parallel with inductor and for this case the better result obtained was also for $10-\mathrm{pF}$ capacitor with an increase in VMD of about $2.04 \mathrm{~V}$ and in respective peak power of approximately $56.40 \%$. The last configuration test was made by using cross-link capacitors and the better result was achieved with $1-\mathrm{pF}$ capacitor, providing an increase of $3.48 \mathrm{~V}$ in VMD and of $103 \%$ approximately in peak power. For all cases tested, the frequency generated at the line output is compromised since it decreases as link capacitance increases. In short, this work shows the prospect of increasing VMD and respectively the peak power employing mainly cross-link configuration for NLTLs. This technique may be very useful for the development of high power NLTLs for applications as pulsed RF sources in electronic disruption systems for small defense platforms in rucks, ships, airplanes, etc.

\section{ACKNOWLEDGMENT}

The authors acknowledge the SOARD/USAF support under contract no. FA9550-14-1-0133.

\section{REFERENCES}

[1] D. Yoshida, H. Ishizawa, T. Tanabe, K. Sugimoto, S. H. R. Hosseini, S. Katsuki and H. Akiyama, "Development of burst high frequency wave source for medical application," in Proc. of the IEEE International Pulsed Power Conference, 2013. p.1-4.

[2] J. D. C. Darling and P. Smith, "High-power pulsed RF extraction from nonlinear lumped element transmission lines," IEEE Trans. Plasma Sci., vol. 36, no. 5, pp. 2598-2603, Oct. 2008.

[3] L. P. Silva Neto, J. O. Rossi, J. J. Barroso and E. Schamiloglu, "Highpower RF generation from nonlinear transmission lines with barium titanate ceramic capacitors," IEEE Trans. Plasma Sci., vol. 44, no. 12. pp. 3424-3431, Nov. 2016.

[4] F. S. Yamasaki, L. P. Silva Neto, J. O. Rossi and J. J. Barroso, "Soliton generation using nonlinear transmission lines," IEEE Trans. Plasma Sci., vol. 42, no. 11, pp. 3471-3477, Nov. 2014.

[5] L. P. Silva Neto, J. O. Rossi, J. J. Barroso, "Pulse sharpening and RF generation using nonlinear transmission lines," in Proc. of the International Microwave and Optoelectronics Conference, 2015, p. 1-6.

[6] N. S. Kuek, A. C. Liew, E. Schamiloglu and J. O. Rossi, "Oscillating pulse generator based on a nonlinear inductive line," IEEE Trans. Plasma Sci., vol. 41, no. 10, pp. 2619-2624, Oct. 2013.

[7] L. P. Silva Neto, J. O. Rossi, J. J. Barroso and F. S. Yamasaki, "RF pulse formation in NLTLs using varactor diode," in Proc. of The Symposium of Operational Applications in Areas of Defense, 2014, p.1-6. 